\title{
Dietary supplementation with olive mill wastewaters induces modifications on chicken jejunum epithelial cell transcriptome and modulates jejunum morphology
}

Marcella Sabino ${ }^{1}$, Katia Cappelli $i^{*}$ (D), Stefano Capomaccio ${ }^{1}$, Luisa Pascucci ${ }^{1}$, Ilaria Biasato ${ }^{2}$, Andrea Verini-Supplizi ${ }^{1}$, Andrea Valiani $^{3}$ and Massimo Trabalza-Marinucci ${ }^{1}$

\begin{abstract}
Background: The Mediterranean diet is considered one of the healthier food habits and olive oil is one of its key components. Olive oil polyphenols are known to induce beneficial effects in several pathological conditions, such as inflammatory bowel disease, and to contrast the proliferation of cancer cells or hypercholesterolemia. Polyphenols are also present in waste products derived from the olive industry: olive mill wastewaters (OMWW) are rich in polyphenols and there is an increasing interest in using OMWW in animal nutrition. OMWW are attributed with positive effects in promoting chicken performance and the quality of food-derived products. However, a tissue-specific transcriptome target analysis of chickens fed with OMWW has never been attempted.
\end{abstract}

Results: We explored the effect of dietary OMWW on the intestinal function in broilers. A morphological analysis of the jejunum revealed that OMWW reduced crypt depth, whereas no significant modifications were observed for villus height and the villus height/crypt depth ratio. An RNA Sequencing analysis was performed on isolated, intestinal, epithelial cells and 280 differentially expressed genes were found using a count-based approach. An enrichment analysis revealed that the majority of up regulated genes in the OMWW group were over-represented by the regulation of viral genome replication-related GO-Terms, whereas down regulated genes were mainly involved in cholesterol and lipid metabolism.

Conclusions: Our study showed how an industrial waste product can be recycled as a feed additive with a positive relapse. OMWW dietary supplementation can be a nutritional strategy to improve chicken performance and health, prevent intestinal damage, enhance innate immunity and regulate cholesterol metabolism and fat deposition.

Keywords: Nutrigenomics, Differentially expressed genes, Anti-viral activity, Cholesterol biosynthesis, Fatty acid metabolism

\footnotetext{
* Correspondence: katia.cappelli@unipg.it

${ }^{1}$ Department of Veterinary Medicine, University of Perugia, Via San Costanzo

4, 06126 Perugia, Italy

Full list of author information is available at the end of the article
}

(c) The Author(s). 2018 Open Access This article is distributed under the terms of the Creative Commons Attribution 4.0 International License (http://creativecommons.org/licenses/by/4.0/), which permits unrestricted use, distribution, and reproduction in any medium, provided you give appropriate credit to the original author(s) and the source, provide a link to the Creative Commons license, and indicate if changes were made. The Creative Commons Public Domain Dedication waiver (http://creativecommons.org/publicdomain/zero/1.0/) applies to the data made available in this article, unless otherwise stated. 


\section{Background}

The Mediterranean diet is the foundation of the cultural identity of the Mediterranean region and is widely recognised for its potential effects in reducing the risk of cancer and cardiovascular, metabolic and neurodegenerative diseases [1, 2]. Many beneficial properties of the Mediterranean diet appear to be related to the high consumption of olive oil. Olive oil is enriched with hydrophilic phenolic compounds, including phenolic acids and derivatives (e.g gallic acid and vanillic acid), flavones (e.g. luteolin), lignans (e.g pinoresinol), secoiridoids (e.g. oleuropeinaglycon), phenolic alcohols (e.g. hydroxytyrosol, tyrosol) [3, 4]. Indeed, the increasing interest in olive oil polyphenols is associated with their biological activities: antioxidant, antiatherogenic, antihepatotoxic, hypoglycemic, anti-inflammatory, antitumor, antiviral and immunomodulating [5-7]. For instance, oleuropein, hydroxytyrosol, tyrosol and caffeic acid are considerable scavengers of reactive oxygen and nitrogen species (ROS and RNS) [8]. Hydroxytyrosol also has potential anti-inflammatory properties, reducing pro-inflammatory signalling in human monocytes [9]. Olive oil polyphenols show versatile properties in metabolic diseases: it has been reported that oleuropein and hydroxytyrosol combat obesity, by reducing the intracellular deposit of triglyceride and decreasing the expression of genes related to the adipogenesis pathway [10-12]. Moreover, olive polyphenols have been reported to reduce glycaemia and cholesterolemia [13]. Olive oil polyphenols have a beneficial effect on the cancer cell line model: in vitro studies reveal that pinoresinol inhibits the proliferation of colon and prostate tumor cells and induces apoptosis in human leukaemia cells [14] Oleuropein, in addition, is capable of preventing colon rectal cancer in mice [15].

Worthy of note is the report that polyphenols help fight inflammatory bowel diseases. In vivo studies state that olive oil phenols prevent colitis in mice [16-18], particularly by activating PPAR signalling, the down regulation of NF- $\kappa B$ signalling and iNOS expression $[17,18]$. In intestinal epithelial cells (Caco-2) exposed to inflammatory stimuli, treatment with polyphenols reduces the expression of $I L-8$ and $N F-K B$ and also affects $I L 8$ mRNA stability by regulating post-transcriptional signalling [19]. These studies clearly state that these compounds can act directly on intestinal epithelial cells, which play an active role against invading pathogens in an immune response and in gastrointestinal tract functions [19-21].

Olive oil polyphenol compounds have also been found in olive mill wastewaters (OMWW), one of the waste products obtained during the olive oil extraction process [22], with a high percentage of hydroxytyrosol, tyrosol, verbascoside and other aglycon derivatives [23-26]. OMWW polyphenols are correlated to antiviral, antibacterial and antifungal activities and they are known to play a role in preventing cardiovascular diseases and tumor progression [27-30]. OMWW polyphenols also possess antioxidant effects on human, intestinal, epithelial cells [31] and show hypoglycaemic effects in diabetic rats [32]. Interestingly, the use of OMWW dietary supplementation is increasing and the aim is to promote animal performance and the quality of derived products. For instance, OMWW dietary supplementation improves the redox status of broilers, by reducing both protein and lipid oxidation and enhancing the activity of antioxidant enzymes [33]. Moreover, the OMWW extract has been proved effective against $P$. fluorescens, which is responsible for the negative, organoleptic properties of mozzarella cheese [26], and has, therefore, been proposed as a functional ingredient in milk for its role in reducing Maillard reaction products [34]. OMWW polyphenols have been also effective in reducing faecal shedding of Campylobacter spp. in broilers [35], which is of particular interest considering that a high number of foodborne disease outbreaks in humans are due to the presence of Campylobacter spp. in poultry meat [36].

Another discovery worthy of support is that olive oil polyphenols have been found in a blend of OMWW and olive cake known as "paté", another olive oil extraction waste product. Paté has also been used as a supplement for poultry and reports have shown its beneficial effects in improving chicken performance and the oxidative status of meat [37].

However, very little is known about the effects of OMWW on the jejunum in broilers and no modern approaches using Next Generation Sequencing techniques have been applied to such a system.

Thus, we propose a nutrigenomic investigation of the effects of a dietary supplement of OMWW on the broiler's jejunum. A morphological characterisation and whole transcriptome analysis of intestinal epithelial cells was applied in order to detect possible changes induced by OMWW dietary supplementation.

\section{Results \\ Morphological analysis of jejunum epithelial cells}

Light and transmission electron microscopy analyses confirmed the epithelial nature of recovered cells. As shown in Fig. 1, collagenase digestion resulted in the isolation of strips of tall cells, consisting of the simple columnar epithelium covering the intestinal villous surface. Columnar cells typically displayed the brush border, formed by closely packed microvilli.

The ultra-structural evaluation of cells collected from control and treated animals did not reveal any difference in terms of subcellular features. The brush border was similarly organised and developed in both groups (Fig. 1).

\section{Histomorphological investigations}

The intestinal morphology of broiler chickens is summarised in Table 1. OMWW inclusion in the diet did 

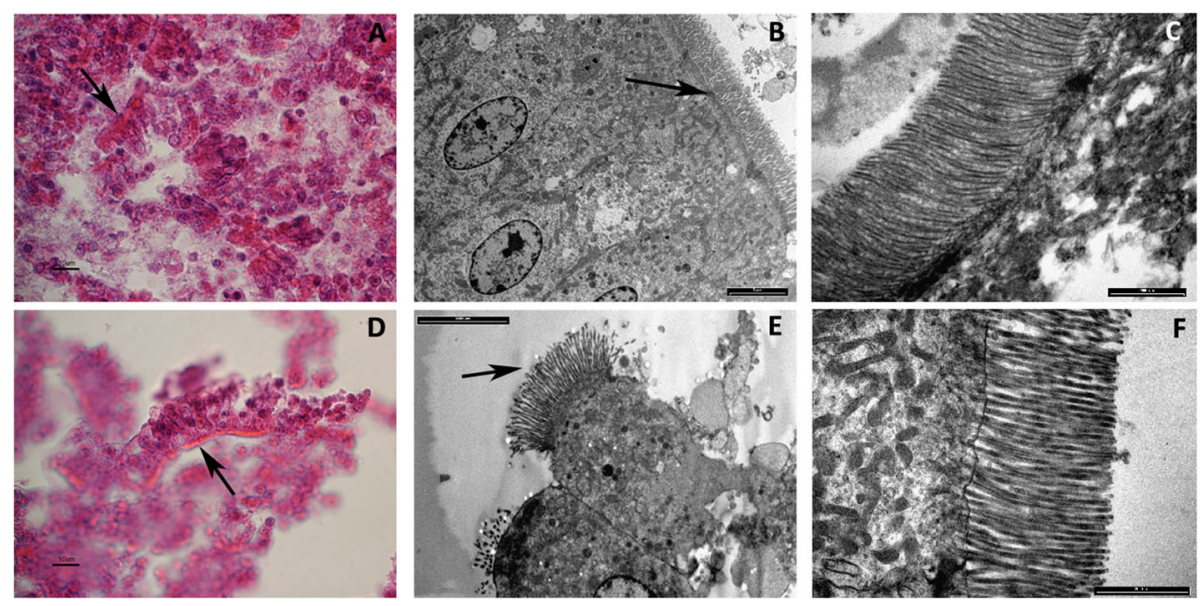

Fig. 1 Light and transmission electron microscopy features of jejunum epithelial cells obtained by collagenase digestion. a and $\mathbf{d}$. Single and grouped epithelial cells of control (a) and treated animals (d). Note the columnar shape and the typical eosinophilic brush border (arrow). Haematoxylin-Eosin, scale bar: $10 \mu \mathrm{m}$. $\mathbf{b}$ and $\mathbf{e}$. Epithelial cell strips obtained by digestion of control (b) and treated jejunum tracts (e). The medium power view reveals the single layer of polarized columnar cells that cover the villous surface. The tall nuclei are lined up at the base of the cells while the apical surface is covered by microvilli (arrow). Transmission electron microscopy. Scale bar, $5000 \mathrm{~nm}$. c and f. High power view of the luminal portion of the epithelial cells obtained by digestion of control (c) and treated jejunum tracts ( $\mathbf{f}$ ). Observe the surface of the columnar epithelial cells with the "brush border" consisting of closely packed microvilli. Transmission electron microscopy. Scale bar, $5000 \mathrm{~nm}$

not significantly affect $(P>0.05)$ the villus height $(\mathrm{Vh})$ and villus height to crypt depth $(\mathrm{Vh} / \mathrm{Cd})$ ratio. On the contrary, broilers fed with OMWW showed a lower $\mathrm{Cd}$ $(P<0.01)$ compared to control group (CTRL).

\section{RNA sequencing data analysis}

The RNA sequencing experiment produced an average of 23 million read pairs per sample. Raw data are published in SRA with accession numbers from SAMN08940088 to SAMN08940106. An average of 18.3 million reads was obtained after trimming and an average of 15.1 million reads (82\%) was uniquely mapped to the chicken reference genome (Gallus gallus v.5.0), with a good representation of the medium-highly expressed genes in the target tissue. Only these reads were used for the differential gene expression assessment to avoid introducing expression bias via a multi-mapper assignment. Detailed statistics on quality control and mapping are shown in Table 2.

Table 1 Effects of OMWW inclusion on intestinal morphometric indexes of broiler chickens ( $n=10 /$ treatment)

\begin{tabular}{lllll}
\hline & CTRL & OMWW & SEM & $P$-value \\
\hline $\mathrm{Vh}_{(\mathrm{mm})}$ & 1.01 & 0.90 & 0.05 & 0.234 \\
$\mathrm{Cd}_{(\mathrm{mm})}$ & $0.07^{\mathrm{a}}$ & $0.06^{\mathrm{b}}$ & 0.00 & 0.004 \\
$\mathrm{Vh} / \mathrm{Cd}_{(\mathrm{mm} / \mathrm{mm})}$ & 14.56 & 15.87 & 0.74 & 0.392 \\
\hline
\end{tabular}

Different superscript letters $(a, b)$ in the same row mean significant differences $(P<0.05)$ among the dietary treatments. Control, CTRL; Olive oil mill wastewaters, (OMWW); $\mathrm{Vh}$, villus height; $\mathrm{Cd}$, crypt depth; $\mathrm{Vh} / \mathrm{Cd}$ ratio, villus height to crypt depth ratio

\section{Differentially expressed genes}

After a statistical analysis with edgeR using a data set of 9162 filtered genes, we found 280 differentially expressed genes (DEG) in the isolated, epithelial cells of the jejunum in the OMWW group compared to the CTRL group, with a significance of adjusted $p$-value ( $\mathrm{q}$-value) $<0.05$ and an absolute log fold change (logFC) of over 1.0. Using these filters, 139 genes were up regulated $(\log F C>1.0)$, whereas 141 genes were down- regulated $(\operatorname{logFC}>-1.0)$. After annotating the differential expressed genes using BioMart, the associated gene names were used to perform an enrichment analysis. All details are shown in the Additional file 1.

\section{Gene functional analysis}

The annotated list from the differential gene expression analysis was used as input for the gene ontology enrichment and pathway analysis. The enrichment according to the three biological vocabularies (Cellular Component, Biological Process and Molecular function) and Kyoto Encyclopaedia of Genes and Genomes (KEGG) pathways was assessed using ClueGO, a Cytoscape plugin.

Most of the down regulated DEGs were over-represented in KEGG pathways (PPAR signalling pathway, Steroid biosynthesis) or GO terms related to lipid metabolism (fatty acid metabolic process, triglyceride metabolic process, cholesterol biosynthetic process, lipid biosynthetic process, phospholipid biosynthetic process, steroid biosynthetic process, and sterol metabolic process).

We also found a massive up regulation of genes enriched for the GO-Terms (regulation of viral process, 
Table 2 RNA Sequencing libraries details

\begin{tabular}{|c|c|c|c|c|}
\hline Sample name & Raw reads & Trimmed & Uniquely Mapped & Uniquely Mapped (\%) \\
\hline$\overline{C T R L} 1$ & 37.039 .265 & 30.103 .595 & 25.238 .297 & $83.84 \%$ \\
\hline CTRL 2 & 28.864 .090 & 23.311 .634 & 19.394 .421 & $83.20 \%$ \\
\hline CTRL 3 & 26.175 .781 & 21.414 .954 & 18.099 .690 & $84.52 \%$ \\
\hline CTRL 4 & 23.819 .919 & 17.978 .157 & 14.694 .053 & $81.73 \%$ \\
\hline CTRL 5 & 27.269 .370 & 21.304 .535 & 17.945 .240 & $84.23 \%$ \\
\hline CTRL 6 & 24.754 .841 & 20.179 .523 & 17.070 .409 & $84.59 \%$ \\
\hline CTRL 7 & 24.595 .313 & 19.973 .641 & 17.020.911 & $85.22 \%$ \\
\hline CTRL 8 & 23.335 .827 & 18.507 .845 & 14.691 .888 & $79.38 \%$ \\
\hline CTRL 9 & 17.593 .049 & 13.053 .838 & 10.563 .297 & $80.92 \%$ \\
\hline CTRL 10 & 15.202 .953 & 10.908 .028 & 8.974 .349 & $82.27 \%$ \\
\hline OMWW 1 & 16.047 .903 & 11.408 .761 & 9.497 .639 & $83.25 \%$ \\
\hline OMWW 2 & 18.438 .802 & 13.501 .457 & 11.200 .681 & $82.96 \%$ \\
\hline OMWW 3 & 18.519 .366 & 15.975 .728 & 12.945 .322 & $81.03 \%$ \\
\hline OMWW 5 & 17.782 .725 & 15.398 .684 & 11.865 .229 & $77.05 \%$ \\
\hline OMWW 6 & 18.273.935 & 15.835 .585 & 12.952 .124 & $81.79 \%$ \\
\hline OMWW 7 & 26.686 .925 & 22.289 .512 & 19.036.201 & $85.40 \%$ \\
\hline OMWW 8 & 21.648 .754 & 18.174 .251 & 15.709 .291 & $86.44 \%$ \\
\hline OMWW 9 & 27.390 .420 & 21.368 .047 & 17.413 .426 & $81.49 \%$ \\
\hline OMWW 10 & 28.732 .976 & 21.833 .209 & 17.909 .295 & $82.03 \%$ \\
\hline
\end{tabular}

regulation of viral life cycle, viral genome replication, regulation of viral genome replication, negative regulation of viral process, response to virus, negative regulation of viral life cycle, negative regulation of viral genome replication) and the KEGG pathway (Influenza $A$ ) of the viral process. All details are reported in Tables 3 and 4.

\section{Discussion}

This study revealed that chicken dietary supplementation with OMWW induces changes at both a morphological and transcriptional level in the jejunum mucosa tract.

These results are of particular interest for the "feed and food" chain, considering that a waste product could be effective in promoting animal healthiness while "recycling".

In detail, the morphological analysis revealed a significant decrease of crypt depth in the jejunal tract of the supplemented group (Table 1) that indicates a decreased turnover of the intestinal epithelium. On the contrary, deeper crypts would indicate faster tissue turnover in response to a damage of villi.

Cell migration from the crypt to the villus apex is a crucial step to balance villus epithelial shedding and maintain tissue homeostasis [38]. On the other hand, increased crypt depth in poultry is associated with small intestine damage due to stress stimuli (e.g. heat stress), which negatively influence functions in digestion and absorption [39].
These observations would allow to hypothesize that OMWW can have a protective effect on the jejunum mucosa. Performance and health status data, however, did not confirm this hypothesis, in that the two groups of birds had similar feed conversion efficiencies (average value: 2.41 ) and no differences in mortality and morbidity rate were recorded (data not shown). In both broilers and growing pigs, it has been observed that the beneficial effects on performance and immune response induced by plant-derived phenolic compounds are more likely to be shown when animals are under stressful environmental conditions $[40,41]$. It must be emphasized that, in the present experiment, all animals were in excellent condition and showed no evidence of disease.

Moreover, the transcriptome analysis of isolated epithelial cells revealed that the incorporation of OMWW into the broiler diet was able to modulate the expression of genes mainly involved in the innate immune response to viral offenses. Compared to the CTRL group, we observed an up regulation of anti-viral genes in OMWW chickens. For example, IKBKE plays a crucial role in regulating antiviral signalling pathways mediated by NF- $\mathrm{BB}$ [42], whereas TLR3 is involved in TLRs signalling for innate and adaptive immune responses [43]. TLR3 is classified as a germline-encoded pattern-recognition receptor (PRR) and acts in recognising a double strand dsRNA virus [44]. The expression of TLR3 is modulated in bowel diseases. For instance, TLR3 is down regulated 
Table 3 Significantly enriched GO Terms for the three vocabularies obtained via ClueGO (FDR < 0.05)

\begin{tabular}{|c|c|c|c|c|}
\hline GO-ID & GO-Term & FDR & Nr. Genes & Associated Genes Found \\
\hline GO:0006066 & alcohol metabolic process & 2,30E-04 & 11,00 & $\begin{array}{l}\text { [ABHD3, CHDH, CHPT1, CYP51A1, } \\
\text { DHCR24, ENPP7, FDPS, HMGCS1, } \\
\text { INSIG1, MSMO1, NSDHL] }\end{array}$ \\
\hline GO:0016126 & sterol biosynthetic process & $2,70 \mathrm{E}-04$ & 5,00 & $\begin{array}{l}\text { [CYP51A1, FDPS, HMGCS1, INSIG1, } \\
\text { MSMO1] }\end{array}$ \\
\hline GO:0000793 & condensed chromosome & $3,30 \mathrm{E}-04$ & 8,00 & $\begin{array}{l}\text { [BRCA1, CENPW, MSH4, NDC80, } \\
\text { NEK2, PLK1, SGOL1, SMC2] }\end{array}$ \\
\hline GO:1901615 & $\begin{array}{l}\text { organic hydroxy compound } \\
\text { metabolic process }\end{array}$ & $3,40 \mathrm{E}-04$ & 13,00 & $\begin{array}{l}\text { [ABHD3, ALDH9A1, BBOX1, CHDH, } \\
\text { CHPT1, CYP51A1, DHCR24, ENPP7, } \\
\text { FDPS, HMGCS1, INSIG1, MSMO1, } \\
\text { NSDHL] }\end{array}$ \\
\hline GO:0008610 & lipid biosynthetic process & $3,70 \mathrm{E}-04$ & 14,00 & $\begin{array}{l}\text { [AGMO, BRCA1, CHPT1, CYP51A1, } \\
\text { FDFT1, FDPS, GPAM, HMGCS1, } \\
\text { INSIG1, MSMO1, NSDHL, PIGA, } \\
\text { PLD1, TCF7L2] }\end{array}$ \\
\hline GO:0016125 & sterol metabolic process & $3,80 \mathrm{E}-04$ & 7,00 & $\begin{array}{l}\text { [CYP51A1, DHCR24, FDPS, HMGCS1, } \\
\text { INSIG1, MSMO1, NSDHL] }\end{array}$ \\
\hline GO:0000794 & $\begin{array}{l}\text { condensed nuclear } \\
\text { chromosome }\end{array}$ & $4,00 \mathrm{E}-04$ & 6,00 & $\begin{array}{l}\text { [BRCA1, MSH4, NDC80, NEK2, PLK1, } \\
\text { SGOL1] }\end{array}$ \\
\hline GO:0008203 & $\begin{array}{l}\text { cholesterol metabolic } \\
\text { process }\end{array}$ & $6,20 \mathrm{E}-04$ & 6,00 & $\begin{array}{l}\text { [CYP51A1, DHCR24, FDPS, HMGCS1, } \\
\text { INSIG1, NSDHL] }\end{array}$ \\
\hline GO:1902652 & $\begin{array}{l}\text { secondary alcohol metabolic } \\
\text { process }\end{array}$ & $6,90 \mathrm{E}-04$ & 6,00 & $\begin{array}{l}\text { [CYP51A1, DHCR24, FDPS, HMGCS1, } \\
\text { INSIG1, NSDHL] }\end{array}$ \\
\hline GO:0006695 & $\begin{array}{l}\text { cholesterol biosynthetic } \\
\text { process }\end{array}$ & $7,20 \mathrm{E}-04$ & 4,00 & [CYP51A1, FDPS, HMGCS1, INSIG1] \\
\hline GO:1902653 & $\begin{array}{l}\text { secondary alcohol } \\
\text { biosynthetic process }\end{array}$ & $7,20 \mathrm{E}-04$ & 4,00 & [CYP51A1, FDPS, HMGCS1, INSIG1] \\
\hline GO:0006577 & $\begin{array}{l}\text { amino-acid betaine metabolic } \\
\text { process }\end{array}$ & 1,10E-03 & 3,00 & {$[\mathrm{ALDH} 9 \mathrm{~A} 1, \mathrm{BBOX} 1, \mathrm{CHDH}]$} \\
\hline GO:0006631 & fatty acid metabolic process & $1,10 \mathrm{E}-03$ & 9,00 & $\begin{array}{l}\text { [AACS, AGMO, BRCA1, ETFA, GPAM, } \\
\text { HADHA, INSIG1, MSMO1, SLC27A4] }\end{array}$ \\
\hline GO:0051297 & centrosome organization & $1,20 \mathrm{E}-03$ & 6,00 & $\begin{array}{l}\text { [BRCA1, HAUS8, NEK2, NPM1, PLK1, } \\
\text { SGOL1] }\end{array}$ \\
\hline GO:0032787 & $\begin{array}{l}\text { monocarboxylic acid } \\
\text { metabolic process }\end{array}$ & $1,20 \mathrm{E}-03$ & 12,00 & $\begin{array}{l}\text { [AACS, AGMO, ALDH9A1, BBOX1, } \\
\text { BRCA1, ETFA, GPAM, HADHA, } \\
\text { INSIG1, MSMO1, SLC27A4, VNN1] }\end{array}$ \\
\hline GO:0098813 & $\begin{array}{l}\text { nuclear chromosome } \\
\text { segregation }\end{array}$ & 1,30E-03 & 8,00 & $\begin{array}{l}\text { [MSH4, NDC80, NEK2, NUSAP1, } \\
\text { PLK1, SGOL1, SMC2, UBE2C] }\end{array}$ \\
\hline GO:0007059 & chromosome segregation & $1,50 \mathrm{E}-03$ & 9,00 & $\begin{array}{l}\text { [BRCA1, MSH4, NDC80, NEK2, } \\
\text { NUSAP1, PLK1, SGOL1, SMC2, } \\
\text { UBE2C] }\end{array}$ \\
\hline GO:0000780 & $\begin{array}{l}\text { condensed nuclear } \\
\text { chromosome, centromeric } \\
\text { region }\end{array}$ & $1,50 \mathrm{E}-03$ & 3,00 & [NDC80, PLK1, SGOL1] \\
\hline GO:0031023 & $\begin{array}{l}\text { microtubule organizing } \\
\text { center organization }\end{array}$ & $1,50 \mathrm{E}-03$ & 6,00 & $\begin{array}{l}\text { [BRCA1, HAUS8, NEK2, NPM1, } \\
\text { PLK1, SGOL1] }\end{array}$ \\
\hline GO:0046165 & alcohol biosynthetic process & $1,60 \mathrm{E}-03$ & 6,00 & $\begin{array}{l}\text { [CHPT1, CYP51A1, FDPS, HMGCS1, } \\
\text { INSIG1, MSMO1] }\end{array}$ \\
\hline GO:0006576 & $\begin{array}{l}\text { cellular biogenic amine } \\
\text { metabolic process }\end{array}$ & $1,60 \mathrm{E}-03$ & 5,00 & $\begin{array}{l}\text { [ABHD3, CHDH, CHPT1, ENPP7, } \\
\text { SMOX] }\end{array}$ \\
\hline GO:0045132 & $\begin{array}{l}\text { meiotic chromosome } \\
\text { segregation }\end{array}$ & $1,90 \mathrm{E}-03$ & 4,00 & [MSH4, PLK1, SGOL1, SMC2] \\
\hline GO:0042439 & $\begin{array}{l}\text { ethanolamine-containing } \\
\text { compound metabolic }\end{array}$ & $2,20 \mathrm{E}-03$ & 4,00 & [ABHD3, CHDH, CHPT1, ENPP7] \\
\hline
\end{tabular}


Table 3 Significantly enriched GO Terms for the three vocabularies obtained via ClueGO (FDR < 0.05) (Continued)

\begin{tabular}{|c|c|c|c|c|}
\hline$\overline{G O}-\mathrm{ID}$ & GO-Term & FDR & Nr. Genes & Associated Genes Found \\
\hline GO:1901617 & $\begin{array}{l}\text { organic hydroxy compound } \\
\text { biosynthetic process }\end{array}$ & 2,20E-03 & 7,00 & $\begin{array}{l}\text { [BBOX1, CHPT1, CYP51A1, FDPS, } \\
\text { HMGCS1, INSIG1, MSMO1] }\end{array}$ \\
\hline GO:0000070 & $\begin{array}{l}\text { mitotic sister chromatid } \\
\text { segregation }\end{array}$ & 2,30E-03 & 6,00 & $\begin{array}{l}\text { [NDC80, NEK2, NUSAP1, PLK1, SMC2, } \\
\text { UBE2C] }\end{array}$ \\
\hline GO:0097164 & $\begin{array}{l}\text { ammonium ion metabolic } \\
\text { process }\end{array}$ & 2,70E-03 & 6,00 & $\begin{array}{l}\text { [ABHD3, ALDH9A1, BBOX1, } \mathrm{CHDH}, \\
\text { CHPT1, ENPPP7] }\end{array}$ \\
\hline GO:0008608 & $\begin{array}{l}\text { attachment of spindle } \\
\text { microtubules to kinetochore }\end{array}$ & 2,80E-03 & 3,00 & [NDC80, NEK2, SGOL1] \\
\hline GO:0000779 & $\begin{array}{l}\text { condensed chromosome, } \\
\text { centromeric region }\end{array}$ & $3,10 \mathrm{E}-03$ & 4,00 & [CENPW, NDC80, PLK1, SGOL1] \\
\hline GO:0045071 & $\begin{array}{l}\text { negative regulation of viral } \\
\text { genome replication }\end{array}$ & $3,10 \mathrm{E}-03$ & 3,00 & [EIF2AK2, OASL, RSAD2] \\
\hline GO:0009308 & amine metabolic process & 4,00E-03 & 5,00 & $\begin{array}{l}\text { [ABHD3, CHDH, CHPT1, ENPP7, } \\
\text { SMOX] }\end{array}$ \\
\hline GO:0003725 & double-stranded RNA binding & 4,00E-03 & 4,00 & [DHX58, EIF2AK2, OASL, TLR3] \\
\hline GO:0008202 & steroid metabolic process & 4,00E-03 & 7,00 & $\begin{array}{l}\text { [CYP51A1, DHCR24, FDPS, HMGCS1, } \\
\text { INSIG1, MSMO1, NSDHL] }\end{array}$ \\
\hline GO:0044106 & $\begin{array}{l}\text { cellular amine metabolic } \\
\text { process }\end{array}$ & 4,10E-03 & 5,00 & $\begin{array}{l}\text { [ABHD3, CHDH, CHPT1, ENPP7, } \\
\text { SMOX] }\end{array}$ \\
\hline GO:0000281 & mitotic cytokinesis & 4,10E-03 & 3,00 & [MITD1, NUSAP1, PLK1] \\
\hline GO:0009615 & response to virus & 4,60E-03 & 8,00 & $\begin{array}{l}\text { [DDX60, DHX58, EIF2AK2, GPAM, } \\
\text { IKBKE, OASL, RSAD2, TLR3] }\end{array}$ \\
\hline GO:0000819 & sister chromatid segregation & 4,70E-03 & 6,00 & $\begin{array}{l}\text { [NDC80, NEK2, NUSAP1, PLK1, SMC2, } \\
\text { UBE2C] }\end{array}$ \\
\hline GO:0000776 & kinetochore & 4,90E-03 & 5,00 & [CENPW, NDC80, NEK2, PLK1, SGOL1] \\
\hline GO:1904030 & $\begin{array}{l}\text { negative regulation of cyclin- } \\
\text { dependent protein kinase } \\
\text { activity }\end{array}$ & 7,70E-03 & 3,00 & [NPM1, PLK1, UBE2C] \\
\hline GO:0008654 & $\begin{array}{l}\text { phospholipid biosynthetic } \\
\text { process }\end{array}$ & $8,40 \mathrm{E}-03$ & 5,00 & [CHPT1, FDPS, GPAM, PIGA, PLD1] \\
\hline GO:0061640 & $\begin{array}{l}\text { cytoskeleton-dependent } \\
\text { cytokinesis }\end{array}$ & $8,50 \mathrm{E}-03$ & 3,00 & [MITD1, NUSAP1, PLK1] \\
\hline GO:0000777 & $\begin{array}{l}\text { condensed chromosome } \\
\text { kinetochore }\end{array}$ & $9,10 \mathrm{E}-03$ & 3,00 & [CENPW, NDC80, PLK1] \\
\hline GO:0045840 & $\begin{array}{l}\text { positive regulation of mitotic } \\
\text { nuclear division }\end{array}$ & $9,10 \mathrm{E}-03$ & 3,00 & [NUSAP1, PLK1, UBE2C] \\
\hline GO:0072330 & $\begin{array}{l}\text { monocarboxylic acid } \\
\text { biosynthetic process }\end{array}$ & $1,00 \mathrm{E}-02$ & 5,00 & $\begin{array}{l}\text { [AGMO, BBOX1, BRCA1, INSIG1, } \\
\text { MSMO1] }\end{array}$ \\
\hline GO:0046486 & glycerolipid metabolic process & 1,20E-02 & 7,00 & $\begin{array}{l}\text { [ABHD3, CHPT1, GPAM, INSIG1, PIGA, } \\
\text { PLD1, TCF7L2] }\end{array}$ \\
\hline GO:0044242 & cellular lipid catabolic process & 1,30E-02 & 5,00 & $\begin{array}{l}\text { [ENPP7, ETFA, GALC, HADHA, } \\
\text { SLC27A4] }\end{array}$ \\
\hline GO:0098661 & $\begin{array}{l}\text { inorganic anion } \\
\text { transmembrane transport }\end{array}$ & 1,30E-02 & 4,00 & $\begin{array}{l}\text { [ANO6, LOC101748788, SLC20A1, } \\
\text { SLC26A2] }\end{array}$ \\
\hline GO:1903901 & $\begin{array}{l}\text { negative regulation of viral } \\
\text { life cycle }\end{array}$ & $1,40 \mathrm{E}-02$ & 3,00 & [EIF2AK2, OASL, RSAD2] \\
\hline GO:0008081 & $\begin{array}{l}\text { phosphoric diester hydrolase } \\
\text { activity }\end{array}$ & $1,40 \mathrm{E}-02$ & 4,00 & [ENPP7, GDPD1, PDE9A, PLD1] \\
\hline GO:0051785 & $\begin{array}{l}\text { positive regulation of nuclear } \\
\text { division }\end{array}$ & $1,40 \mathrm{E}-02$ & 3,00 & [NUSAP1, PLK1, UBE2C] \\
\hline GO:0051607 & defense response to virus & $1,50 \mathrm{E}-02$ & 6,00 & $\begin{array}{l}\text { [DDX60, DHX58, GPAM, OASL, } \\
\text { RSAD2, TLR3] }\end{array}$ \\
\hline GO:0006633 & fatty acid biosynthetic process & 1,50E-02 & 4,00 & [AGMO, BRCA1, INSIG1, MSMO1] \\
\hline
\end{tabular}


Table 3 Significantly enriched GO Terms for the three vocabularies obtained via ClueGO (FDR < 0.05) (Continued)

\begin{tabular}{|c|c|c|c|c|}
\hline$\overline{G O}-\mathrm{ID}$ & GO-Term & FDR & Nr. Genes & Associated Genes Found \\
\hline GO:0015103 & $\begin{array}{l}\text { inorganic anion } \\
\text { transmembrane transporter } \\
\text { activity }\end{array}$ & $1,50 \mathrm{E}-02$ & 4,00 & $\begin{array}{l}\text { [ANO6, LOC101748788, SLC20A1, } \\
\text { SLC26A2] }\end{array}$ \\
\hline GO:0045069 & $\begin{array}{l}\text { regulation of viral genome } \\
\text { replication }\end{array}$ & $1,50 \mathrm{E}-02$ & 3,00 & [EIF2AK2, OASL, RSAD2] \\
\hline GO:0000922 & spindle pole & $1,50 \mathrm{E}-02$ & 4,00 & [NEK2, NPM1, PLK1, SGOL1] \\
\hline GO:0048806 & genitalia development & $1,60 \mathrm{E}-02$ & 3,00 & [DHCR24, KLHL10, TCF7L2] \\
\hline GO:0048525 & $\begin{array}{l}\text { negative regulation of viral } \\
\text { process }\end{array}$ & $1,70 \mathrm{E}-02$ & 3,00 & [EIF2AK2, OASL, RSAD2] \\
\hline GO:1902850 & $\begin{array}{l}\text { microtubule cytoskeleton } \\
\text { organization involved in } \\
\text { mitosis }\end{array}$ & $1,80 \mathrm{E}-02$ & 3,00 & [NDC80, NEK2, PLK1] \\
\hline GO:0000775 & $\begin{array}{l}\text { chromosome, centromeric } \\
\text { region }\end{array}$ & $1,90 \mathrm{E}-02$ & 5,00 & [CENPW, NDC80, NEK2, PLK1, SGOL1] \\
\hline GO:0022626 & cytosolic ribosome & $2,10 \mathrm{E}-02$ & 4,00 & [RP11-849F2.7, RPL21, RPL9, RPS23] \\
\hline GO:0043901 & $\begin{array}{l}\text { negative regulation of multi- } \\
\text { organism process }\end{array}$ & $2,10 \mathrm{E}-02$ & 4,00 & [DHX58, EIF2AK2, OASL, RSAD2] \\
\hline GO:1901989 & $\begin{array}{l}\text { positive regulation of cell } \\
\text { cycle phase transition }\end{array}$ & $2,10 \mathrm{E}-02$ & 3,00 & [NPM1, PLK1, UBE2C] \\
\hline GO:0006641 & triglyceride metabolic process & $2,10 \mathrm{E}-02$ & 3,00 & [GPAM, INSIG1, TCF7L2] \\
\hline GO:0090068 & $\begin{array}{l}\text { positive regulation of cell } \\
\text { cycle process }\end{array}$ & 2,20E-02 & 5,00 & $\begin{array}{l}\text { [BRCA1, NPM1, NUSAP1, PLK1, } \\
\text { UBE2C] }\end{array}$ \\
\hline GO:0009062 & fatty acid catabolic process & 2,30E-02 & 3,00 & [ETFA, HADHA, SLC27A4] \\
\hline GO:0016614 & $\begin{array}{l}\text { oxidoreductase activity, acting } \\
\text { on } \mathrm{CH}-\mathrm{OH} \text { group of donors }\end{array}$ & 2,30E-02 & 4,00 & {$[\mathrm{CHDH}, \mathrm{DHCR} 24, \mathrm{HADHA}, \mathrm{NSDHL}]$} \\
\hline GO:0035725 & $\begin{array}{l}\text { sodium ion transmembrane } \\
\text { transport }\end{array}$ & 2,30E-02 & 4,00 & [ANO6, CNKSR3, SLC2OA1, STOML1] \\
\hline GO:0019079 & viral genome replication & 2,30E-02 & 3,00 & [EIF2AK2, OASL, RSAD2] \\
\hline GO:0007126 & meiotic nuclear division & $2,40 \mathrm{E}-02$ & 4,00 & [MSH4, PLK1, SGOL1, SMC2] \\
\hline GO:0022625 & $\begin{array}{l}\text { cytosolic large ribosomal } \\
\text { subunit }\end{array}$ & $2,60 \mathrm{E}-02$ & 3,00 & [RP11-849F2.7, RPL21, RPL9] \\
\hline GO:0045017 & $\begin{array}{l}\text { glycerolipid biosynthetic } \\
\text { process }\end{array}$ & $2,60 \mathrm{E}-02$ & 4,00 & [CHPT1, PIGA, PLD1, TCF7L2] \\
\hline GO:0006639 & $\begin{array}{l}\text { acylglycerol metabolic } \\
\text { process }\end{array}$ & $2,70 \mathrm{E}-02$ & 3,00 & [GPAM, INSIG1, TCF7L2] \\
\hline GO:0045444 & fat cell differentiation & $2,80 \mathrm{E}-02$ & 5,00 & $\begin{array}{l}\text { [FNDC5, INSIG1, PEX11A, SOCS1, } \\
\text { TCF7L2] }\end{array}$ \\
\hline GO:0015698 & inorganic anion transport & $2,80 \mathrm{E}-02$ & 4,00 & $\begin{array}{l}\text { [ANO6, LOC101748788, SLC20A1, } \\
\text { SLC26A2] }\end{array}$ \\
\hline GO:0006638 & $\begin{array}{l}\text { neutral lipid metabolic } \\
\text { process }\end{array}$ & $2,80 \mathrm{E}-02$ & 3,00 & [GPAM, INSIG1, TCF7L2] \\
\hline GO:0007051 & spindle organization & $2,80 \mathrm{E}-02$ & 4,00 & [HAUS8, NDC80, NEK2, PLK1] \\
\hline GO:0007098 & centrosome cycle & $3,00 \mathrm{E}-02$ & 3,00 & [BRCA1, NEK2, NPM1] \\
\hline GO:0005254 & chloride channel activity & $3,00 \mathrm{E}-02$ & 3,00 & [ANO6, LOC101748788, SLC26A2] \\
\hline GO:1903046 & meiotic cell cycle process & $3,00 \mathrm{E}-02$ & 4,00 & [MSH4, PLK1, SGOL1, SMC2] \\
\hline GO:0007052 & mitotic spindle organization & $3,30 \mathrm{E}-02$ & 3,00 & [NDC80, NEK2, PLK1] \\
\hline GO:0051092 & $\begin{array}{l}\text { positive regulation of NF- } \\
\text { kappaB transcription factor } \\
\text { activity }\end{array}$ & 3,30E-02 & 3,00 & [EIF2AK2, NPM1, TLR3] \\
\hline GO:0004386 & helicase activity & $3,40 \mathrm{E}-02$ & 4,00 & [DDX60, HELB, MOV10, PIF1] \\
\hline GO:0072329 & $\begin{array}{l}\text { monocarboxylic acid catabolic } \\
\text { process }\end{array}$ & $3,40 \mathrm{E}-02$ & 3,00 & [ETFA, HADHA, SLC27A4] \\
\hline
\end{tabular}


Table 3 Significantly enriched GO Terms for the three vocabularies obtained via ClueGO (FDR < 0.05) (Continued)

\begin{tabular}{|c|c|c|c|c|}
\hline GO-ID & GO-Term & FDR & Nr. Genes & Associated Genes Found \\
\hline GO:0004620 & phospholipase activity & $3,40 \mathrm{E}-02$ & 3,00 & [ABHD3, ENPP7, PLD1] \\
\hline GO:0051983 & $\begin{array}{l}\text { regulation of chromosome } \\
\text { segregation }\end{array}$ & $3,40 \mathrm{E}-02$ & 3,00 & {$[\mathrm{NEK} 2, \mathrm{PLK} 1, \mathrm{UBE} 2 \mathrm{C}]$} \\
\hline GO:0010565 & $\begin{array}{l}\text { regulation of cellular ketone } \\
\text { metabolic process }\end{array}$ & $3,50 \mathrm{E}-02$ & 3,00 & [BRCA1, INSIG1, TCF7L2] \\
\hline GO:1902476 & $\begin{array}{l}\text { chloride transmembrane } \\
\text { transport }\end{array}$ & $3,60 \mathrm{E}-02$ & 3,00 & [ANO6, LOC101748788, SLC26A2] \\
\hline GO:0051321 & meiotic cell cycle & $3,60 \mathrm{E}-02$ & 4,00 & [MSH4, PLK1, SGOL1, SMC2] \\
\hline GO:0051225 & spindle assembly & $3,60 \mathrm{E}-02$ & 3,00 & [HAUS8, NEK2, PLK1] \\
\hline GO:0005253 & anion channel activity & $3,70 \mathrm{E}-02$ & 3,00 & [ANO6, LOC101748788, SLC26A2] \\
\hline GO:2001251 & $\begin{array}{l}\text { negative regulation of } \\
\text { chromosome organization }\end{array}$ & 3,70E-02 & 3,00 & [BRCA1, PIF1, PLK1] \\
\hline GO:0015297 & antiporter activity & $3,90 \mathrm{E}-02$ & 3,00 & [LOC101748788, SLC26A2, SLC7A4] \\
\hline GO:0015108 & $\begin{array}{l}\text { chloride transmembrane } \\
\text { transporter activity }\end{array}$ & $3,90 \mathrm{E}-02$ & 3,00 & [ANO6, LOC101748788, SLC26A2] \\
\hline GO:0050660 & $\begin{array}{l}\text { flavin adenine dinucleotide } \\
\text { binding }\end{array}$ & $3,90 \mathrm{E}-02$ & 3,00 & [CHDH, DHCR24, ETFA] \\
\hline GO:0051053 & $\begin{array}{l}\text { negative regulation of DNA } \\
\text { metabolic process }\end{array}$ & 4,00E-02 & 3,00 & [ENPP7, PIF1, POLQ] \\
\hline GO:1904029 & $\begin{array}{l}\text { regulation of cyclin- } \\
\text { dependent protein kinase } \\
\text { activity }\end{array}$ & $4,50 \mathrm{E}-02$ & 3,00 & [NPM1, PLK1, UBE2C] \\
\hline GO:0008286 & $\begin{array}{l}\text { insulin receptor signaling } \\
\text { pathway }\end{array}$ & $4,80 \mathrm{E}-02$ & 3,00 & {$[\mathrm{IRS} 4, \mathrm{KL}, \mathrm{SOCS} 1]$} \\
\hline
\end{tabular}

GO-ID GO term accession number, GOTerm name of Gene Ontology Term, FDR (False Discovery Rate) after Benjamini-Hochberg correction, Nr. Genes number of input genes found per term, Associated Genes Found associated name of genes found per term

in intestinal epithelial cells in patients affected by Crohn's disease [45].

EIF2AK2, OASL and $M X$ are known as interferon-stimulated genes (ISGs) with anti-viral activity: EIF2AK2 is involved in dsRNA virus recognition and inhibits viral protein production [46]. An in vivo study reveals an increment of mortality of mice knock-out for EIF2AK2 infected by West Nile Virus, which is an important zoonotic pathogen $[47,48]$ The $O A S L$ gene encodes anti-viral proteins, which hinder virus replication [49], whereas MX is a GTPase belonging to the dynamin family, which interferes with the activity of viral polymerases to contrast the virus replication cycle [50].

It has been reported that EIF $2 A K 2, O A S L, M X$ and melanoma differentiation-associated protein 5 (MDA5) expression is modulated by the infectious bursal disease virus, which causes a major disease with a negative economic impact in the poultry industry [42]. MDA5 is also involved in the recognition of Avian influenza virus, another important cause of a high chicken mortality rate [51]. It shows anti-viral activity, in which it probably interacts with the ATP-dependent RNA helicase (DHX58)

Table 4 Significantly enriched KEGG pathways obtained via ClueGO (FDR <0.05)

\begin{tabular}{lllll}
\hline ID & KEGG pathway & FDR & Nr. Genes & Associated Genes Found \\
\hline KEGG:0000100 & Steroid biosynthesis & $1,60 \mathrm{E}-04$ & 5,00 & [CYP51A1, DHCR24, FDFT1, MSMO1, NSDHL] \\
KEGG:0005164 & Influenza A & $4,60 \mathrm{E}-03$ & 7,00 & [EIF2AK2, FDPS, IKBKE, KPNA2, MX1, RSAD2, TLR3] \\
KEGG:0000280 & $\begin{array}{l}\text { Valine, leucine and isoleucine } \\
\text { degradation }\end{array}$ & $6,90 \mathrm{E}-03$ & 4,00 & [AACS, ALDH9A1, HADHA, HMGCS1] \\
& Butanoate metabolism & $8,50 \mathrm{E}-03$ & 3,00 & [AACS, HADHA, HMGCS1] \\
KEGG:0000650 & beta-Alanine metabolism & $9,90 \mathrm{E}-03$ & 3,00 & [ALDH9A1, HADHA, SMOX] \\
KEGG:0000410 & Lysine degradation & $3,40 \mathrm{E}-02$ & 3,00 & [ALDH9A1, BBOX1, HADHA] \\
KEGG:0000310 & PPAR signaling pathway & $4,50 \mathrm{E}-02$ & 3,00 & [FP325317.1, MMP1, SLC27A4] \\
\hline
\end{tabular}

ID GO term accession number, KEGG pathway name of KEGG pathway, FDR (False Discovery Rate) after Benjamini-Hochberg correction, Nr. Genes number of input genes found per term, Associated Genes Found associated name of genes found per term 
[51]. All these genes were significant DEG in our analysis, providing evidence that OMWW supplementation acted in modulating anti-viral genes and suggested that an increased expression of anti-viral genes could be effective in contrasting virus replication and act as a mechanism to elude a host innate immune response. Infectious bursal disease virus recognition is inhibited by a viral protein (VP3), which prevents MDA5 binding with the viral genome [52]. On the other hand, the coronavirus strategy to evade host defences is to establish a concentration-dependent competition between the viral proteins and host proteins in favour of the virus, by reducing the transcription of host anti-viral genes [53]. We could speculate that an increment of the host protein expression mediated by an OMWW supplementation might revert the viral-host protein ratio in favour of the host.

Another mechanism to limit viral replication by the host is to modify the cell membrane lipids, which restrict the virus budding process. Interestingly, the RSAD2 gene, up regulated in the OMWW group, appears to use precisely this mechanism [54] to limit West Nile Virus replication [55] and a wide range of other viruses, such as hepatitis C, HIV, the influenza virus and human cytomegalovirus [55-59].

$R S A D 2$ influences the fluidity of the membrane inhibiting farnesyl diphosphate synthase (FDPS) activity, which plays a role in cholesterol and isoprenoid biosynthesis [60]. It is interesting to note that our DEG analysis shows RSAD2 up regulated in the OMWW group, whereas FDPS is down regulated. We can suppose that a down regulation of FDPS could initially be related not only to a greater activity of RSAD2, but also to OMWW supplementation effects on lipid metabolism, bearing in mind that FDPS is mainly involved in cholesterol and steroid metabolism [60].

FDPS is actually enriched for cholesterol metabolic process, lipid, steroid and sterol biosynthetic process related GO-Terms with other down regulated DEG: (3-Hydroxy-3-methylglutaryl-coenzyme A (CoA) synthase 1 (HMGCS1), farnesyl-diphosphate farnesyltransferase 1(FDFT1), NAD(P) dependent steroid dehydrogenase-like (NSDHL), Cytochrome P450 Family 51 Subfamily A Member 1 (CYP51A1).

HMGCS1, NSDHL and FDFT1 encode 3-Hydroxy-3methylglutaryl-CoA synthase, squalene synthase and $\mathrm{NAD}(\mathrm{P}) \mathrm{H}$ sterol dehydrogenase, respectively, which are all key enzymes involved in different steps of cholesterol biosynthesis $[61,62]$ and some of which are modulated in obesity [63].

Taken as a whole, these results support the hypothesis that OMWW can also affect sterol synthesis pathway-related genes. This hypothesis is intriguing, as the balance of sterol absorption and de novo synthesis regulates cholesterol homeostasis in the intestine [64]. It has been reported that after the liver, the small intestine is the second tissue to contribute to de novo sterol synthesis in rodents, whereas in other species, such as rabbits and guinea pigs, it is the most important source, with the intestinal epithelium having the greatest synthetic capacity [65-68].

The down regulation of sterol biosynthesis reported in our study, however, suggests that OMWW could be a beneficial, nutritional strategy. This is confirmed by the known hypocholesterolemic effects of polyphenol-rich, olive mill wastewaters observed in rats fed with cholesterolrich diets [69].

Moreover, FDPS, NSDHL and FDFT1 are candidate genes to regulate fat deposition in chickens: excessive fat deposition in chickens is associated with negative effects on poultry production, in terms of feed efficiency [70]. It has also been reported that FDPS, NSDHL and FDFT1 are up regulated in the fat line chickens and in liver and adipose tissue in fast growing chickens [71, 72].

Worthy of note is the presence of a modulating effect on lipid metabolism in jejunum epithelial cells due to OMWW, which is supported by a down regulation of Matrix Metalloproteinase 1 (MMP-1) and Fatty Acid Binding Protein 3 (FABP-3). As shown in our analysis, we found $M M P-1$ enriched PPAR signalling KEGG pathways. $M M P-1$ is involved in fatty acid oxidation and its expression is usually up regulated in inflammatory bowel disease $[73,74]$. FABP-3, on the other hand, which belongs to genes of the FABP family, is involved in the transport of fatty acids [74-76].

Overall, these results support the suggestion that OMWW could have a beneficial effect in preventing intestinal damage and in reducing fatty acid transportation, with a subsequent decrease of body fat accumulation, which represents a critical issue in the chicken industry [70].

If we also take into consideration the results from the morphological analysis, our findings support the suggestion that OMWW supplementation could have positive effect on growth performance, since intestinal health is associated with improved nutrient digestibility [77].

\section{Conclusion}

Our results revealed that OMWW dietary supplementation in poultry farming might be a good strategy to promote a small intestine response to damage, stimulate innate immunity and improve chicken health. In addition, the down regulation of genes mainly involved in cholesterol metabolism and fatty acid transport suggests that the use of OMWW might be extended to other livestock species to regulate sterol metabolism and fat deposition. The down regulation of genes involved in lipid metabolism observed in our study suggests that the analysis of the effects of dietary OMWW on liver and adipose tissue, which are 
important nutrigenomic target tissues, could be a further objective of this research.

Nevertheless, given the promising results already obtained from this first study, the use of OMWW as an additive in animal diets is an important aspect to consider in terms of circular economy and environmental impact. More interestingly, these findings showed that OMWW dietary supplementation is a good strategy to reuse a waste product, by exploiting the beneficial effects associated to its polyphenol content.

\section{Methods}

\section{Experimental design}

A total of 102 22-day-old female broilers (Ross 308) were reared in a conventional poultry house located in Umbria region, Italy. All broilers were randomly divided in two experimental group fed with two different diets for 20 days. One group was fed with a commercial feed (CTRL), while the other one was fed with a CTRL diet supplemented with $0.03 \%$ of olive mill wastewater (OMWW). To obtain the dietary supplement to be included in the poultry feed, OMWW was processed through the use of a filtration system with progressive permeability membranes [25] and finally dehydrated using a spry-drying system. Feed analyses were performed according to AOAC [78] and metabolisable energy was calculated according to Carré and Rozo [79]. The diet details are shown in Table 5 .

The entire trial was performed according to the European Directive 2010/63/EU on animal welfare.

\section{Isolation of jejunum epithelial cells and jejunum histological characterisation}

At slaughter, the entire small intestine was excised and a $10 \mathrm{~cm}$-long segment of jejunum was cut, in order to isolate epithelial cells. The lumen was flushed with $30 \mathrm{ml}$ of washing solution, composed of sterile, ice-cold PBS, supplemented with $200 \mathrm{U} / \mathrm{mL}$ penicillin, $200 \mu \mathrm{g} / \mathrm{mL}$ streptomycin, $12.5 \mu \mathrm{g} / \mathrm{mL}$ amphotericin B (Sigma, St. Louis, MO, USA) and $10 \mu \mathrm{g} / \mathrm{mL}$ gentamicin (Euroclone, Milan, Italy). Both ends of each jejunum tract were clumped after being filled with pre-warmed $0.1 \%$ collagenase type I (Wortighton. Lakewood, NJ, USA). After $10 \mathrm{~min}$ of incubation at $37{ }^{\circ} \mathrm{C}$, each sample was unclamped and the enzymatic solution containing mucosal epithelial cells was recovered and centrifuged at $300 \mathrm{~g}$ for $10 \mathrm{~min}$. Cells were suspended in $1 \mathrm{ml}$ of PureZOL (BioRad, CA, USA) and stored at $-80{ }^{\circ} \mathrm{C}$ until RNA isolation.

\section{Morphological analysis of isolated cells}

Isolated cells were analysed both by light and transmission electron microscopy. For this purpose, they were fixed with $10 \%$ buffered formalin, paraffin embedded,
Table 5 Ingredients of the control ${ }^{a}$ grower-finisher diet

\begin{tabular}{ll}
\hline Ingredients (kg/100 kg) & \\
Maize & 47.51 \\
Soybean meal (44\% crude protein) & 33.95 \\
Wheat shorts & 7.00 \\
Whole roasted soybean & 6.00 \\
Soybean oil & 2.40 \\
Calcium carbonate & 1.42 \\
Dicalcium phosphate & 0.64 \\
Mineral and vitamin premix & \\
Sodium chloride & 0.50 \\
Enzymes & 0.30 \\
Chemical composition (kg/100 kg) & 0.25 \\
Dry matter & 87.81 \\
Crude protein & 21.16 \\
Ether extracts & 6.03 \\
Ash & 5.87 \\
Neutral detergent fiber & 11.63 \\
Acid detergent fiber & 4.84 \\
Lignin & 0.82 \\
Starch & 31.81 \\
Metabolisable energy (Kcal/kg) & 3120 \\
\hline In the OMwW diet, 0.03\% of olive mill waste water was substituted for \\
0.03\% maize \\
bIntegrations per Kg of feed: vitamin A 13500 U.l.; vitamin D3 U.I. 3750; ferrous \\
carbonate mg 93.2; anhydrous calcium iodate mg 2.3; copper sulfate \\
pentahydrate mg 59; manganese oxide 51.6 mg; manganese sulphate \\
monohydrate mg 123.2; zinc oxide 93 mg; sodium selenite mg 0.4 \\
\hline
\end{tabular}

sectioned at $5 \mu \mathrm{m}$ thickness, and stained with haematoxylin \& eosin (H\&E) for light microscopy observation. For the electron microscopy analysis, isolated cells were fixed with $2.5 \%$ glutaraldehyde in $0.1 \mathrm{M}$ phosphate buffer, $\mathrm{pH} 7.3$, for $1 \mathrm{~h}$ at room temperature, post-fixed in $2 \%$ osmium tetroxide, dehydrated in a graded series of ethanol up to absolute, pre-infiltrated and embedded in Epon 812. Ultrathin sections $(90 \mathrm{~nm})$ were mounted on 200-mesh copper grids, stained with uranyl acetate and lead citrate, and examined by a Philips EM 208.

\section{Histomorphological investigations of jejunum samples}

Samples of jejunum were fixed in a $10 \%$ buffered formalin solution for morphometric investigations. Tissues were routinely embedded in paraffin wax blocks, sectioned at a thickness of $5 \mu \mathrm{m}$, mounted on glass slides and stained with H\&E. The evaluated morphometric indexes included the villus height (Vh, from the tip of the villus to the crypt), the crypt depth (Cd, from the base of the villus to the submucosa) and the villus height to crypt depth $(\mathrm{Vh} / \mathrm{Cd})$ ratio [80]. Morphometric analyses were performed on 10, well-oriented, intact villi and 10 
crypts, chosen from the intestinal segments collected [81].

The statistical analysis was performed using the GraphPad $^{\circ}$ Prism software (v. 6). The Shapiro-wilk test established normal data distribution. A student's $t$ test was used to compare the morphometric indexes between the dietary treatments. Significance was declared at $P<$ 0.05 . The results were expressed as mean and pooled standard error of the mean (SEM).

\section{RNA extraction}

The total RNA from all 20 jejunum epithelial cell samples was isolated according to the Aurum Total RNA Fatty and Fibrous Tissue kit instructions (BioRad, CA, USA). The genomic DNA from each sample was removed using DNAse treatment, according to the TURBO DNAse manufacturer's specifications (Ambion - Life Technologies, CA, USA). In order to deactivate the DNAse activity, each sample of RNA was then purified using the phenol-chloroform-isoamyl alcohol method, according to the Sambrook et al. protocol [82].

The RNA quantity and quality were evaluated using a NanoDrop 2000 spectrophotometer (Thermo Fisher Scientific, Waltham, MA, USA) and Qubit 2.0 Flurometer (Life Technologies, MA, USA), whereas RNA integrity was carried out by microfluidic electrophoresis on a BioAnalyzer 2100 (Agilent Technologies).

The RNA Integrity Number (RIN) score of the CTRL group was ranging from 3.9 to 6.9 (mean $5.7 \pm 1.1$ ); while the OMWW RIN value was ranging from 2.3 to 5.6 (mean $4.3 \pm 0.8$ ). One sample (OMWW4) was excluded at this step because of a RIN too low (2.30) to prepare a reliable sequencing library.
The low value of RIN is related to some degradation caused by the manipulation procedures for the isolation of the fresh intestinal epithelial cells (see the previous paragraph). However, as detailed in the Results, the percentage of mapping revealed that the RIN values were acceptable for our experiment.

Preparation of the libraries and RNA sequencing data analysis The 19 RNA-Sequencing directional libraries were prepared according to the NEBNext Ultra RNA library kit for Illumina sequencing, using poly-A mRNA magnetic isolation (New England Biolabs, MA, USA). The sequencing process was carried out in one single lane of an Illumina HiSeq 4000 platform, generating 150 base-paired end reads.

The quality of raw and cleaned sequences was checked using FastQC (http://www.bioinformatics.babraham.ac.uk/projects/fastqc/). Quality filtering and adapter removal were performed using a Trimmomatic v.0.35 [83]. The reads were aligned using STAR v.2.4.0.1 [84] to the chicken Ensembl reference genome (Gallus gallusv.5.0).

ReadCounter (http://www.genefriends.org/ReadCounter/references/) was used to quantify the number of read mappings on each gene locus using Galgal5 Ensembl (90) annotation coordinates.

Differentially expressed genes and gene ontology analyses Differentially expressed genes between CTRL and OMWW were evaluated by implementing a negative binomial distribution model in edgeR package (v.3.12.1) [85]. We filtered out features with a low number of reads per sample: one count-per-million in mover $50 \%$ of the samples was required to keep locus. Therefore, a total of 9162-filtered transcripts were used as input into

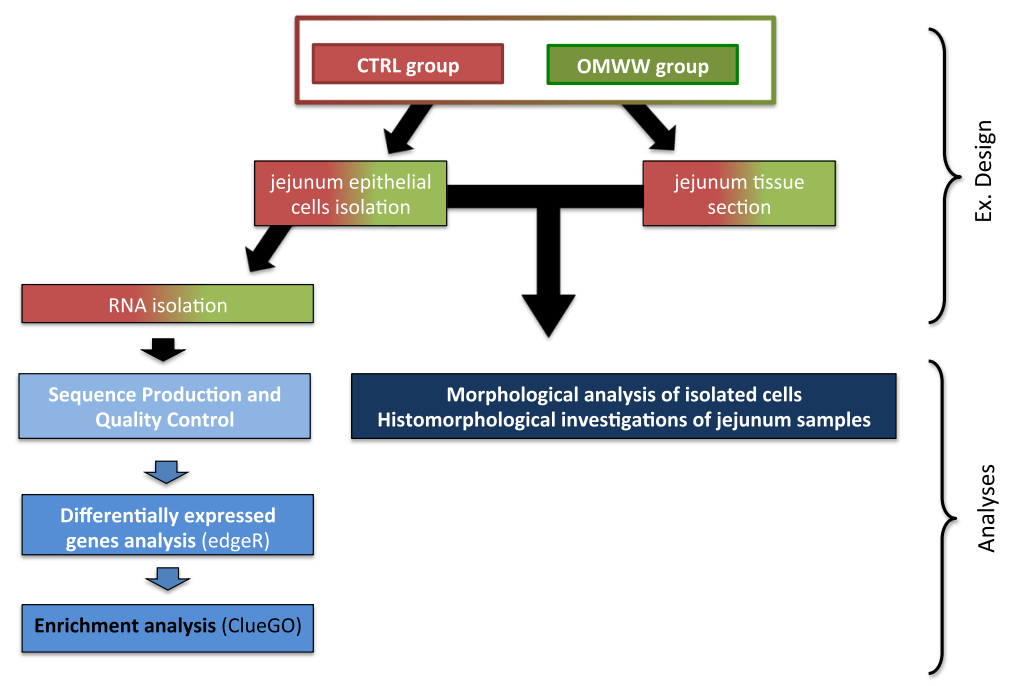

Fig. 2 Experimental design and data analysis workflow 
edgeR. The analyses comprised 10 CTRL and 9 OMWW samples and we considered only the DEG with adjusted $p$-value (q-value) lower than 0.05 and absolute log Fold Change $(\operatorname{logFC})>1.0$ as statistically significant.

Results were annotated using BioMart (http://www.ensembl.org/biomart/martview) and a curated list was used to carry out Gene Ontology (GO) enrichment and pathway analysis using ClueGO 3.2.0, a Cytoscape 3.3.0 plugin [86]. We considered GO-Term (Cellular Component - CC -, Biological Process - BP -, Molecular Function - MF -) and Kyoto Encyclopaedia of Genes and Genomes (KEGG) pathways with False Discovery Rate $(\mathrm{FDR})<0.05$, using Benjamin-Hochberg correction as being statistically significant.

The workflow used in our study is shown in Fig. 2.

\section{Additional file}

Additional file 1: Table S1. Significant differentially expressed genes $(\mathrm{DEG})$, up regulated $(\log F C>1)$ and down regulated $(\log F C<-1)$ in OMWW group. Information contained in the table are significant Gene ID, GalgalEnsembl gene id (e.g. data ENSGALG00000041621); Transcript ID, GalgalEnsembl transcript id (e.g. data ENSGALT00000059872); Gene name, associated name of genes (e.g. LY6E); Gene description, description of gene name (e.g. Lymphocyte Antigen 6 Family Member); logFC, log Fold Change (e.g. 4,44E + 00); $\log C P M, \log _{2}$ counts-per-million (e.g. 8,92E + 00); PValue, $p$-value evaluated in multiple testing (e.g. 3,96E-08); q-value, adjusted p-value (e.g. 2,41E-05). (XLSX 91 kb)

\section{Abbreviations}

BP: Biological processes; CC: Cellular component; Cd: Crypt depth; CTRL: Control; DEG: Differentially expressed genes; FDR: False discovery rate; GO: Gene ontology; H\&E: Haematoxylin \& eosin; KEGG: Kyoto encyclopaedia of genes and genomes; logFC: Absolute log fold change; MF: Molecular function; OMWW: Olive mill wastewaters; q-value: Adjusted p-value; RIN: RNA Integrity number; SEM: Standard error of the mean; Vh: Villus height

\section{Acknowledgements}

The authors thank Gianluca Alunni for technical support.

\section{Funding}

The research was part of the project "Studio e sviluppo di molecole ad azione immunomodulante con lo scopo di ridurre gli antibiotici e/o altri chemioterapici"' (IZSUM 03/14 RC) funded by the Italian Ministry of Health. The funder had no role in study design, data collection and analysis, decision to publish, or preparation of the manuscript.

\section{Availability of data and materials}

The data supporting the conclusions of this article are within the paper and its additional files. Raw sequence data are deposited in SRA with accession numbers from SAMN08940088 to SAMN08940106.

\section{Authors' contributions}

MTM conceived and designed the experiment; MS, KC and SC conceived the kind of data analyses. MS, KC, SC, LP, IB performed the experiments. MS, SC and KC analysed RNA Sequencing data, performed and interpreted bioinformatics and functional analysis; MS, LP and IB performed and interpreted morphological and histological data. AV provided reagents/ materials/RNA sequencing and supervised the writing of the manuscript. MS, KC, SC, LP, IB, AVS and MTM drafted the manuscript. All authors critically revised the manuscript for important intellectual content and all approved the final version of this manuscript.

\section{Ethics approval and consent to participate}

The study was conducted in accordance with the European recommendations for the protection of animals used for scientific purposes (EU Directive 2010/63/EU) and approved by the Italian Ministry of Health (Authorisation n. 506/2016 - PR).

\section{Consent for publication}

Not applicable.

Competing interests

The authors declare that they have no competing interests.

\section{Publisher's Note}

Springer Nature remains neutral with regard to jurisdictional claims in published maps and institutional affiliations.

\section{Author details}

${ }^{1}$ Department of Veterinary Medicine, University of Perugia, Via San Costanzo 4, 06126 Perugia, Italy. ${ }^{2}$ Department of Veterinary Sciences, University of Torino, Largo Paolo Braccini 2, 10095 Grugliasco, Italy. ${ }^{3}$ Istituto Zooprofilattico Sperimentale dell'Umbria e delle Marche, Via Gaetano Salvemini 1, 06126 Perugia, Italy.

Received: 21 November 2017 Accepted: 26 July 2018

Published online: 02 August 2018

References

1. Corella D, Ordovás JM. How does the Mediterranean diet promote cardiovascular health? Current progress toward molecular mechanisms: genediet interactions at the genomic, transcriptomic, and epigenomic levels provide novel insights into new mechanisms. BioEssays. 2014;36:526-37.

2. Stefani M, Rigacci S. Beneficial properties of natural phenols: highlight on protection against pathological conditions associated with amyloid aggregation. Biofactors. 2014;40:482-93.

3. Rigacci S, Stefani M. Nutraceutical Properties of Olive Oil Polyphenols. An Itinerary from Cultured Cells through Animal Models to Humans. Int J Mol Sci [Internet]. 2016 [cited 2017 Sep 12];17. Available from: http://www.ncbi. nlm.nih.gov/pmc/articles/PMC4926377/

4. Servili M, Esposto S, Fabiani R, Urbani S, Taticchi A, Mariucci F, et al. Phenolic compounds in olive oil: antioxidant, health and organoleptic activities according to their chemical structure. Inflammopharmacology. 2009;17:76-84.

5. Tripoli E, Giammanco M, Tabacchi G, Di Majo D, Giammanco S, La Guardia M. The phenolic compounds of olive oil: structure, biological activity and beneficial effects on human health. Nutr Res Rev. 2005;18:98-112.

6. Fabiani R, Rosignoli P, De Bartolomeo A, Fuccelli R, Servili M, Montedoro GF, et al. Oxidative DNA damage is prevented by extracts of olive oil, hydroxytyrosol, and other olive phenolic compounds in human blood mononuclear cells and HL60 cells. J Nutr. 2008;138:1411-6.

7. Tundis R, Loizzo MR, Menichini F, Statti GA, Menichini F. Biological and pharmacological activities of iridoids: recent developments. Mini Rev Med Chem. 2008;8:399-420.

8. de la Puerta R, Martínez Domínguez ME, Ruíz-Gutíerrez V, Flavill JA, Hoult JR. Effects of virgin olive oil phenolics on scavenging of reactive nitrogen species and upon nitrergic neurotransmission. Life Sci. 2001;69:1213-22.

9. Zhang $X$, Cao J, Zhong L. Hydroxytyrosol inhibits pro-inflammatory cytokines, iNOS, and COX-2 expression in human monocytic cells. Naunyn Schmiedeberg's Arch Pharmacol. 2009;379:581-6.

10. Hao J, Shen W, Yu G, Jia H, Li X, Feng Z, et al. Hydroxytyrosol promotes mitochondrial biogenesis and mitochondrial function in 3T3-L1 adipocytes. J Nutr Biochem. 2010;21:634-44.

11. Kim Y, Choi Y, Park T. Hepatoprotective effect of oleuropein in mice: mechanisms uncovered by gene expression profiling. Biotechnol J. 2010;5: 950-60.

12. Drira R, Chen S, Sakamoto K. Oleuropein and hydroxytyrosol inhibit adipocyte differentiation in 3 T3-L1 cells. Life Sci. 2011;89:708-16.

13. Priore P, Caruso D, Siculella L, Gnoni GV. Rapid down-regulation of hepatic lipid metabolism by phenolic fraction from extra virgin olive oil. Eur J Nutr. 2015;54:823-33.

14. Sepporta MV, Mazza T, Morozzi G, Fabiani R. Pinoresinol inhibits proliferation and induces differentiation on human HL60 leukemia cells. Nutr Cancer. 2013;65:1208-18. 
15. Sepporta MV, Fuccelli R, Rosignoli P, Ricci G, Servili M, Fabiani R. Oleuropein prevents Azoxymethane-induced Colon crypt dysplasia and leukocytes DNA damage in a/J mice. J Med Food. 2016;

16. Takashima T, Sakata Y, Iwakiri R, Shiraishi R, Oda Y, Inoue N, et al. Feeding with olive oil attenuates inflammation in dextran sulfate sodium-induced colitis in rat. J Nutr Biochem. 2014;25:186-92.

17. Sánchez-Fidalgo S, Cárdeno A, Sánchez-Hidalgo M, Aparicio-Soto M, de la Lastra CA. Dietary extra virgin olive oil polyphenols supplementation modulates DSS-induced chronic colitis in mice. J Nutr Biochem. 2013;24: 1401-13.

18. Sánchez-Fidalgo S, Sánchez de Ibargüen L, Cárdeno A, Alarcón de la Lastra C. Influence of extra virgin olive oil diet enriched with hydroxytyrosol in a chronic DSS colitis model. Eur J Nutr. 2012;51:497-506.

19. Muto E, Dell'Agli M, Sangiovanni E, Mitro N, Fumagalli M, Crestani M, et al. Olive oil phenolic extract regulates interleukin-8 expression by transcriptional and posttranscriptional mechanisms in Caco-2 cells. Mol Nutr Food Res. 2015;59:1217-21.

20. Brown SJ, Mayer L. The immune response in inflammatory bowel disease. Am J Gastroenterol. 2007;102:2058-69.

21. Kaiser $A$, Willer T, Steinberg P, Rautenschlein S. Establishment of an in vitro intestinal epithelial cell culture model of avian origin. Avian Dis. 2017;61: 229-36.

22. Cardinali A, Cicco N, Linsalata V, Minervini F, Pati S, Pieralice M, et al. Biological activity of high molecular weight phenolics from olive mill wastewater. J Agric Food Chem. 2010;58:8585-90.

23. Khoufi S, Aloui F, Sayadi S. Extraction of antioxidants from olive mill wastewater and electro-coagulation of exhausted fraction to reduce its toxicity on anaerobic digestion. J Hazard Mater. 2008;151:531-9.

24. Dermeche S, Nadour M, Larroche C, Moulti-Mati F, Michaud P. Olive mill wastes: biochemical characterizations and valorization strategies. Process Biochem. 2013;48:1532-52.

25. Servili M, Esposto S, Veneziani G, Urbani S, Taticchi A, Di Maio I, et al. Improvement of bioactive phenol content in virgin olive oil with an olivevegetation water concentrate produced by membrane treatment. Food Chem. 2011;124:1308-15.

26. Roila R, Branciari R, Ranucci D, Ortenzi R, Urbani S, Servili M, et al. Antimicrobial Activity of Olive Mill Wastewater Extract Against Pseudomonas fluorescens Isolated from Mozzarella Cheese. Ital J Food Saf [Internet]. 2016 [cited 2017 Sep 22];5. Available from: http://www.ncbi.nlm.nih.gov/pmc/ articles/PMC5076743/

27. Aziz NH, Farag SE, Mousa LA, Abo-Zaid MA. Comparative antibacterial and antifungal effects of some phenolic compounds. Microbios. 1998;93:43-54.

28. Léger CL, Kadiri-Hassani N, Descomps B. Decreased superoxide anion production in cultured human promonocyte cells (THP-1) due to polyphenol mixtures from olive oil processing wastewaters. J Agric Food Chem. 2000;48:5061-7.

29. Owen RW, Mier W, Giacosa A, Hull WE, Spiegelhalder B, Bartsch H. Phenolic compounds and squalene in olive oils: the concentration and antioxidant potential of total phenols, simple phenols, secoiridoids, lignansand squalene. Food Chem Toxicol. 2000;38:647-59.

30. Obied HK, Allen MS, Bedgood DR, Prenzler PD, Robards K, Stockmann R. Bioactivity and analysis of biophenols recovered from olive mill waste. J Agric Food Chem. 2005;53:823-37.

31. Manna C, Galletti P, Cucciolla V, Moltedo O, Leone A, Zappia V. The protective effect of the olive oil polyphenol (3,4-Dihydroxyphenyl)- ethanol counteracts reactive oxygen metabolite-induced cytotoxicity in Caco-2 cells. J Nutr. 1997;127:286-92.

32. Hamden K, Allouche N, Damak M, Elfeki A. Hypoglycemic and antioxidant effects of phenolic extracts and purified hydroxytyrosol from olive mill waste in vitro and in rats. Chem Biol Interact. 2009;180:421-32.

33. Gerasopoulos K, Stagos D, Kokkas S, Petrotos K, Kantas D, Goulas P, et al. Feed supplemented with byproducts from olive oil mill wastewater processing increases antioxidant capacity in broiler chickens. Food Chem Toxicol. 2015:82:42-9.

34. Troise AD, Fiore A, Colantuono A, Kokkinidou S, Peterson DG, Fogliano V. Effect of olive mill wastewater phenol compounds on reactive carbonyl species and Maillard reaction end-products in ultrahigh-temperature-treated milk. J Agric Food Chem. 2014;62:10092-100.

35. Branciari R, Ranucci D, Ortenzi R, Roila R, Trabalza-Marinucci M, Servili M, et al. Dietary Administration of Olive Mill Wastewater Extract Reduces Campylobacter spp. Prevalence in Broiler Chickens. Sustainability. 2016;8:837.
36. European Food Safety Authority, European Centre for Disease Prevention and Control. The European Union summary report on trends and sources of zoonoses, zoonotic agents and food-borne outbreaks in 2013. EFSA J. 2015; 13:51-58.

37. Branciari R, Galarini R, Giusepponi D, Trabalza-Marinucci M, Forte C, Roila R, et al. Oxidative status and presence of bioactive compounds in meat from chickens fed polyphenols extracted from olive oil industry waste. Sustainability. 2017:9:1566.

38. Williams JM, Duckworth CA, Burkitt MD, Watson AJM, Campbell BJ, Pritchard DM. Epithelial cell shedding and barrier function. Vet Pathol. 2015;52:445-55.

39. Liu L, Fu C, Yan M, Xie H, Li S, Yu Q, et al. Resveratrol modulates intestinal morphology and HSP70/90, NF-KB and EGF expression in the jejunal mucosa of black-boned chickens on exposure to circular heat stress. Food Funct. 2016;7:1329-38.

40. Akbarian A, Michiels J, Degroote J, Majdeddin M, Golian A, De Smet S. Association between heat stress and oxidative stress in poultry; mitochondrial dysfunction and dietary interventions with phytochemicals. J AnimSci Biotechnol. 2016;7:37.

41. Forte C, Ranucci D, Beghelli D, Branciari R, Acuti G, Todini L, et al. Dietary integration with oregano (Origanum vulgare L.) essential oil improves growth rate and oxidative status in outdoor-reared, but not indoor-reared, pigs. J Anim Physiol Anim Nutr (Berl). 2017;101:e352-61.

42. Hui RK, Leung FC. Differential expression profile of chicken embryo fibroblast DF-1 cells infected with cell-adapted infectious Bursal disease virus. PLoS One. 2015;10:e0111771.

43. Cario E, Rosenberg IM, Brandwein SL, Beck PL, Reinecker HC, Podolsky DK. Lipopolysaccharide activates distinct signaling pathways in intestinal epithelial cell lines expressing toll-like receptors. J Immunol. 2000;164:966-72.

44. Akira S, Uematsu S, Takeuchi O. Pathogen recognition and innate immunity. Cell. 2006;124:783-801.

45. Cario E, Podolsky DK. Differential alteration in intestinal epithelial cell expression of toll-like receptor 3 (TLR3) and TLR4 in inflammatory bowe disease. Infect Immun. 2000;68:7010-7.

46. Niso-Santano M, Shen S, Adjemian S, Malik SA, Mariño G, Lachkar S, et al. Direct interaction between STAT3 and EIF2AK2 controls fatty acid-induced autophagy. Autophagy. 2013;9:415-7.

47. Wang J, Yang J, Ge J, Hua R, Liu R, Li X, et al. Newcastle disease virusvectored West Nile fever vaccine is immunogenic in mammals and poultry. Virol J. 2016;13:109.

48. Samuel MA, Whitby K, Keller BC, Marri A, Barchet W, Williams BRG, et al. PKR and RNase $L$ contribute to protection against lethal West Nile virus infection by controlling early viral spread in the periphery and replication in neurons. J Virol. 2006;80:7009-19.

49. Melchjorsen J, Kristiansen H, Christiansen R, Rintahaka J, Matikainen S, Paludan SR, et al. Differential regulation of the OASL and OAS1 genes in response to viral infections. J Interf Cytokine Res. 2009;29:199-207.

50. Haller $\mathrm{O}$, Staeheli $\mathrm{P}$, Kochs G. Interferon-induced $\mathrm{mx}$ proteins in antiviral host defense. Biochimie. 2007;89:812-8.

51. Liniger M, Summerfield A, Zimmer G, McCullough KC, Ruggli N. Chicken cells sense influenza a virus infection through MDA5 and CARDIF signaling involving LGP2. J Virol. 2012;86:705-17.

52. Ye C, Jia L, Sun Y, Hu B, Wang L, Lu X, et al. Inhibition of antiviral innate immunity by birnavirus VP3 protein via blockage of viral double-stranded RNA binding to the host cytoplasmic RNA detector MDA5. J Virol. 2014;88:11154-65.

53. Frieman M, Yount B, Heise M, Kopecky-Bromberg SA, Palese P, Baric RS. Severe acute respiratory syndrome coronavirus ORF6 antagonizes STAT1 function by sequestering nuclear import factors on the rough endoplasmic reticulum/Golgi membrane. J Virol. 2007;81:9812-24.

54. Fitzgerald KA. The interferon inducible gene: Viperin. J Interf Cytokine Res. 2011:31:131-5.

55. Szretter K, Brien JD, Thackray LB, Virgin HW, Cresswell P, Diamond MS. The interferon-inducible gene viperin restricts West Nile virus pathogenesis. J Virol. 2011;85:11557-66.

56. Chin KC, Cresswell P. Viperin (cig5), an IFN-inducible antiviral protein directly induced by human cytomegalovirus. Proc Natl Acad Sci U S A. 2001;98:15125-30.

57. Helbig KJ, Lau DT-Y, Semendric L, Harley HAJ, Beard MR. Analysis of ISG expression in chronic hepatitis $C$ identifies viperin as a potential antiviral effector. Hepatology. 2005:42:702-10

58. Rivieccio MA, Suh H-S, Zhao Y, Zhao M-L, Chin KC, Lee SC, et al. TLR3 ligation activates an antiviral response in human fetal astrocytes: a role for viperin/cig5. J Immunol. 2006;177:4735-41. 
59. Wang $X$, Hinson ER, Cresswell P. The interferon-inducible protein viperin inhibits influenza virus release by perturbing lipid rafts. Cell Host Microbe. 2007;2:96-105

60. Szkopińska A, Płochocka D. Farnesyl diphosphate synthase; regulation of product specificity. Acta Biochim Pol. 2005;52:45-55.

61. Liu XY, Dangel AW, Kelley Rl, Zhao W, Denny P, Botcherby M, et al. The gene mutated in bare patches and striated mice encodes a novel 3betahydroxysteroid dehydrogenase. Nat Genet. 1999;22:182-7.

62. Serquiña AKP, Kambach DM, Sarker O, Ziegelbauer JM. Viral MicroRNAs repress the cholesterol pathway, and 25 -Hydroxycholesterol inhibits infection. MBio. 2017;8

63. Ding J, Reynolds LM, Zeller T, Müller C, Lohman K, Nicklas BJ, et al. Alterations of a cellular cholesterol metabolism network are a molecular feature of obesity-related type 2 diabetes and cardiovascular disease. Diabetes. 2015;64:3464-74.

64. Abumrad NA, Davidson NO. Role of the gut in lipid homeostasis. Physiol Rev. 2012;92:1061-85.

65. Spady DK, Dietschy JM. Sterol synthesis in vivo in 18 tissues of the squirrel monkey, Guinea pig, rabbit, hamster, and rat. J Lipid Res. 1983;24:303-15.

66. Dietschy JM, Turley SD, Spady DK. Role of liver in the maintenance of cholesterol and low density lipoprotein homeostasis in different animal species, including humans. J Lipid Res. 1993;34:1637-59.

67. Xie C, Turley SD, Dietschy JM. ABCA1 plays no role in the centripetal movement of cholesterol from peripheral tissues to the liver and intestine in the mouse. J Lipid Res. 2009;50:1316-29.

68. McFarlane MR, Liang G, Engelking LJ. Insig proteins mediate feedback inhibition of cholesterol synthesis in the intestine. J Biol Chem. 2014;289: 2148-56.

69. Fki I, Sahnoun Z, Sayadi S. Hypocholesterolemic effects of phenolic extracts and purified Hydroxytyrosol recovered from olive mill wastewater in rats fed a cholesterol-rich diet. J Agric Food Chem. 2007;55:624-31.

70. Zhao S, Ma H, Zou S, Chen W, Zhao R. Hepatic lipogenesis in broiler chickens with different fat deposition during embryonic development. J Vet Med A Physiol Pathol Clin Med. 2007;54:1-6.

71. Claire D'Andre H, Paul W, Shen X, Jia X, Zhang R, Sun L, et al. Identification and characterization of genes that control fat deposition in chickens. J Anim Sci Biotechnol. 2013;4:43.

72. Resnyk CW, Carré W, Wang X, Porter TE, Simon J, Le Bihan-Duval E, et al. Transcriptional analysis of abdominal fat in genetically fat and lean chickens reveals adipokines, lipogenic genes and a link between hemostasis and leanness. BMC Genomics. 2013;14:557.

73. Meijer MJW, Mieremet-Ooms M a. C, van der Zon AM, van Duijn W, van Hogezand RA, Sier CFM, et al. Increased mucosal matrix metalloproteinase$1,-2,-3$ and -9 activity in patients with inflammatory bowel disease and the relation with Crohn's disease phenotype. Dig Liver Dis. 2007;39:733-9.

74. Yin F, Yu H, Lepp D, Shi X, Yang X, Hu J, et al. Transcriptome Analysis Reveals Regulation of Gene Expression for Lipid Catabolism in Young Broilers by Butyrate Glycerides. PLoS One [Internet]. 2016 [cited 2017 Sep 13];11. Available from: http://www.ncbi.n/m.nih.gov/pmc/articles/ PMC4979964/

75. Shi Y, He M. Differential gene expression identified by RNA-Seq and GPCR in two sizes of pearl oyster (Pinctada fucata). Gene. 2014,538:313-22.

76. Larkina TA, Sazanova AL, Fomichev KA, Barkova OI, Sazanova AA, Malwski T, et al. Expression profiling of candidate genes for abdominal fat mass in domestic chicken Gallus gallus. Genetika. 2011;47:1140-4.

77. Rinttilä T, Apajalahti J. Intestinal microbiota and metabolites_implications for broiler chicken health and performance1. J Appl Poult Res. 2013:22:647-58.

78. AOAC. Official Methods of Analysis, Association of Official Analytical Chemists Inc:: Arlington, VA, USA, 2000; 17th ed. William Horwitz; 2000

79. Carré B, Rozo E. Predicting the dietary energy value of raw materials used in poultry production. La prédiction de la valeur énergétique des matières premières destinées à l' aviculture. 1990.

80. Laudadio V, Passantino L, Perillo A, Lopresti G, Passantino A, Khan RU, et al. Productive performance and histological features of intestinal mucosa of broiler chickens fed different dietary protein levels. Poult Sci. 2012;91:265-70.

81. Qaisrani SN, Moquet PCA, van Krimpen MM, Kwakkel RP, Verstegen MWA, Hendriks WH. Protein source and dietary structure influence growth performance, gut morphology, and hindgut fermentation characteristics in broilers. Poult Sci. 2014;93:3053-64.

82. Sambrook J, Russell DW, Russell D. Plasmids and their usefulness in molecular cloning. Mol Cloning. 2001;1(1):31-5.
83. Bolger AM, Lohse M, Usadel B. Trimmomatic: a flexible trimmer for Illumina sequence data. Bioinformatics. 2014:30:2114-20.

84. Dobin A, Davis CA, Schlesinger F, Drenkow J, Zaleski C, Jha S, et al. STAR: ultrafast universal RNA-seq aligner. Bioinformatics. 2013;29:15-21.

85. Robinson MD, McCarthy DJ, Smyth GK. edgeR: a bioconductor package for differential expression analysis of digital gene expression data. Bioinformatics. 2010;26:139-40.

86. Bindea G, Mlecnik B, Hackl H, Charoentong P, Tosolini M, Kirilovsky A, et al. ClueGO: a Cytoscape plug-in to decipher functionally grouped gene ontology and pathway annotation networks. Bioinformatics. 2009;25:1091-3.
Ready to submit your research? Choose BMC and benefit from:

- fast, convenient online submission

- thorough peer review by experienced researchers in your field

- rapid publication on acceptance

- support for research data, including large and complex data types

- gold Open Access which fosters wider collaboration and increased citations

- maximum visibility for your research: over $100 \mathrm{M}$ website views per year

At $\mathrm{BMC}$, research is always in progress.

Learn more biomedcentral.com/submissions 